\title{
REVIEWS
}

\section{MORE OLD LECTURES}

LECTURES IN MEDICAL GENETICS. Edited by D. Y-Y. Hsai. Year Book Medical Publishers, Inc. $64 s$.

One of the hazards of audio-visual aids is that the sounds and symbols of the lecture can more readily survive out of sight and earshot of the classroom.

Last year, or perhaps earlier (there are few references after I964), the Medical faculty of Northwestern University had a course of lectures on medical genetics. This seems to have been well planned and certainly started well (lecture (i) "The Structure of the Cell"). As in most other University courses in genetics some lectures were good, others (such as lecture (ii) on chromosomes) were not, and almost all will be obsolete in a few years. The reviewer can see no value in the ritual embalming of such lectures, particularly in a field well served (for the price of this book) by paperbacks, periodicals and the scientific monthlies with their reprint services. As always, embalming turns out to be surprisingly expensive and takes up room at the expense of the living.

J. H. EDWARDs.

\section{A CLASSIC AS AN ELEGANT PAPERBACK}

AN INTRODUCTION TO MEDICAL GENETICS. J. A. Fraser Roberts. 4th edition. Paperback. Oxford University Press, London. 1967. 25s.

It is good to see so soon the fourth edition of this excellent book and interesting to find that in spite of the increasing complexity of the subject the author can still express the basic essentials in precise and lucid English, and keep the additions within bounds-in fact there are only $7 \frac{1}{2}$ more pages than in 1963 and the general layout is similar.

In the chromosome section there are now detailed descriptions of trisomy I 7-18, trisomy I $^{-1} 5$ and of the cri du chat syndrome (but not of "anti-mongolism") and in abnormalities of the sex chromosomes XYY males, with their useful let-out for criminal tendencies, are also mentioned.

There is a new and much more definite account of the inheritance of harelip and cleft palate and it now seems certain that harelip, whether or not cleft palate is present in addition, is multifactorially controlled. This means that more precise genetic advice can be given if the incidence in relatives and in the general population is known. Congenital pyloric stenosis, with its very unusual sex ratio ( 5 boys to every girl) also gives clear evidence of multifactorial control, but owing to the sex effect the incidence in the sisters and daughters of women patients is roo times higher than in the general population-which is exactly what one would expect with multifactorial inheritance. These clinical conditions in fact form most excellent models with which to explain to doctors the intricacies of multifactorial inheritance, and no one has done this better than Fraser Roberts. In pyloric stenosis, before the days of the very successful Ramstedt's operation, 45 years ago, mortality was very high, but it has now been found 2 F 3 